\title{
What skills and knowledge do university mathematics teacher education programs give future teachers in Costa Rica?
}

\author{
Helen Alfaro ${ }^{1}$ and Jorma Joutsenlahti ${ }^{1}$ \\ ${ }^{1}$ Faculty of Education and Culture, Tampere University, Tampere, Finland \\ For correspondence: helen.alfaroviquez@tuni.fi
}

\begin{abstract}
:
High-quality teaching is crucial for improving mathematics education. Teaching mathematics requires specific knowledge, including knowledge of both content and pedagogy. In this study, we analyzed the knowledge for teaching mathematics among 80 future teachers from four mathematics teacher education programs in Costa Rica. Using the Teacher Education and Development Study in Mathematics (TEDS-M) questionnaire, we studied the opportunities to learn the programs provide and the participants' performance in tests of their mathematical content and pedagogical knowledge. The results showed that all the teaching programs involved gave more emphasis to the topics covered in tertiary level mathematics than to aspects of general and mathematics pedagogy. Moreover, the results highlighted the variation among universities in the participants' performance in the tests and demonstrated that the number and content of the courses taken was not correlated with the participants' performance. These findings offer insights to the Costa Rican government and policymakers into the actual structure, variability, and characteristics of teacher education programs, which could serve as a tool for making decisions on measures to improve the quality of teaching.
\end{abstract}

Keywords: mathematics teacher education, mathematical content knowledge, mathematical pedagogical content knowledge, TEDS-M, opportunities to learn (OTL)

\section{Introduction}

In Costa Rica, the quality of mathematics teaching in primary and secondary education has been the subject of recent discussion, especially after students' poor performance in mathematics in the PISA test (see PISA 2018 results in OECD, 2019) and national tests. The report "Costa Rica: The state of public teaching policies" (Román \& Lentini, 2018) and the study "The state of education" (Programa Estado de la Nación (PEN), 2019) investigated the teaching situation in Costa Rica and what was needed to improve its quality. The documents highlighted three main issues. One was the lack of control of the variation and quality of the teacher education programs. A second was poor teacher recruitment policies and ineffective measures for assessing teaching quality. Finally, the PEN (2019) study stated that more attention should be paid to teaching and education management in order to improve the education system. The study suggested, among other initiatives, the elaboration of a national framework of qualifications for education majors and the implementation of a suitability test for the recruitment of teachers. According to Schmidt (2011b), recruitment and selection are crucial for developing well-prepared and qualified teachers. Further, Tatto et al. (2012) found that strong quality assurance arrangements tend to ensure the creation and maintenance of a high-quality teaching workforce.

Hence, one of the requirements is to define the desired teaching competencies of pre-service and inservice mathematics teachers in Costa Rica. Considering a competence as a group of aptitudes and skills a person must have to master his or her job, including both cognitive abilities and beliefs, Blömeke and Kaiser (2014) affirmed that teaching competencies motivate teachers' performance in the class. Therefore, enhancing teachers' competencies is crucial to improving education. In this article, we will focus on studying future teachers' cognitive abilities.

When analyzing mathematics teacher education programs (TEPs), it is important to know what knowledge is considered necessary for the role. In 1986, Lee Shulman (1986) presented crucial ideas 
regarding the knowledge categories important for teaching, including subject content knowledge and subject pedagogical content knowledge. His ideas have been the basis of many studies concerning the mathematical knowledge needed for teaching (e.g., Rowland et al., 2009; Ball et al., 2008; Kilpatrick et al., 2015). However, according to Hoover et al. (2016), no "theoretically grounded, well defined, and shared conception" (p. 3) of mathematical knowledge for teaching exists. One reason is that the knowledge categories are intertwined, and it is difficult to draw a line separating one from the other. Nevertheless, the knowledge for teaching mathematics has been studied extensively, from its composition and development to the effects of teachers' knowledge on teaching and students' learning (Hoover et al., 2016). Some studies have found that the content of the teacher education programs influences the teachers' knowledge (Schmidt et al., 2011b). Teachers' knowledge informs their ways of teaching, which in turn affects the way students learn (Hill et al., 2005). Consequently, the students' achievement is indirectly affected by the contents of the TEPs (Monk, 1994).

Despite the many studies that have been conducted on the same theme, only a few have been developed with teachers at the secondary level and only three in Latin America (Hoover et al., 2016). For instance, in the Teacher Education and Development Study in Mathematics (TEDS-M), in which 17 countries participated, only one was from Latin America, and that country ended up with the lowest performance on the test of mathematical content knowledge and mathematical pedagogical content knowledge.

Therefore, this article focuses on the problems of teaching mathematics in Costa Rica, specifically the importance of understanding the content and pedagogical knowledge of teachers and how the teaching of mathematics can be improved in order to enhance students' learning and performance. In addition, it aims to explore the lack of studies on the subject in Latin America, to describe the opportunities to learn offered by the different mathematics TEPs in Costa Rica, and to study future teachers' mathematical knowledge for teaching, using the TEDS-M questionnaire. By so doing, we hope to provide information that can be used by policymakers and university authorities to improve the educational system.

\section{Knowledge for teaching mathematics}

In his attempt to understand "the knowledge that grows in the minds of teachers," Shulman (1986, p. 9) distinguished three categories of related knowledge: subject matter content knowledge, pedagogical content knowledge, and curricular knowledge. According to Shulman, subject matter content knowledge concerns the amount and organization of the knowledge, involving more than just concepts and facts but requiring also a comprehension of the subject matter's structure, rules, and functioning. Pedagogical content knowledge "includes knowledge of how to represent, explain and teach the subject matter, as well as an understanding of how children learn the subject and common obstacles to this learning"(Kaarstein, 2014, p. 30). Curricular knowledge entails knowledge of the topics to teach and their organization and connections, as well as the guidelines or standards for implementing them. Moreover, it involves the books and teaching materials available for teaching the content.

Following Shulman's ideas, many researchers have set about refining the definition of the professional knowledge specific for teaching mathematics. For instance, Ball and her colleagues from the University of Michigan have developed a framework of mathematical knowledge for teaching (Ball et al., 2008), and other authors have defined knowledge for teaching using different names for the categories (e.g., Rowland et al., 2007; O'Meara, 2010). Therefore, although there is no agreement on the definitions, language, and basic concepts for the mathematical knowledge for teaching (Hoover et al., 2016), there is a consensus about the competencies for teaching mathematics. These competencies are encompassed in "(i) mathematical knowledge, (ii) pedagogical knowledge related to teaching mathematics, and (iii) general pedagogical knowledge related to instructional practices and schooling" (Schmidt et al., 2011b, p. 1266). For the TEDS-M, the authors defined a theoretical framework, which identifies three factors as quality indicators that have an impact on teacher education outcomes. They are content courses in mathematics, professional preparation for teaching mathematics, and experiences of teaching methods, and they are measured by studying opportunities to learn (OTL) (Blömeke, 2012). Moreover, they assess 
future teacher performance in mathematical content knowledge and mathematical pedagogical content knowledge by means of a test.

Teacher Education and Development Study in Mathematics (TEDS-M): theoretical framework

The TEDS-M is a large comparative study carried out in 2008 with the participation of 17 countries, under the auspices of the International Association for the Evaluation of Educational Achievement (IEA). It investigates "the opportunities provided and taken by future teachers while engaged in teacher preparation toward developing the competencies deemed by the literature to be relevant to quality classroom instruction" (Schmidt et al., 2011a, p. 139). For studying teacher preparation, the TEDS-M examines the participants' opportunities to learn, in terms of content studied and teaching methods experienced. Regarding mathematical knowledge for teaching, the TEDS-M framework entails two constructs for the test: mathematical content knowledge and pedagogical content knowledge (Tatto et al., 2008).

Opportunities to learn (OTL): The TEDS-M framework considers opportunities to learn as the content of TEPs that future teachers study. The questionnaire investigates the OTL in mathematics content, mathematical pedagogy, and general pedagogy. Courses on mathematical content have been shown to be a quality indicator of a TEP; however, they are only the foundation for mathematics teachers (Blömeke, 2012). Therefore, the framework also includes courses on professional preparation for teaching specific to mathematics and in general. In addition, it considers the teaching methods that the participants experience and the opportunities they have to plan and teach classes. These three elements clearly have an impact on the outcomes of teacher education (Blömeke, 2012).

Mathematical content knowledge (MCK): This corresponds to what Shulman (1986) refers to as subject matter content knowledge. To evaluate future teachers' mathematical knowledge, it was important in the TEDS-M framework to define what knowledge was considered necessary for lower secondary mathematics teachers in different countries. The TEDS-M study uses the same framework of content and cognitive domain as the Trends in International Mathematics and Science Study (TIMSS) data for lower secondary teaching. The TIMSS framework, which is used for designing tasks to be taught at this level, includes four categories of content domain: number, algebra, geometry, and data (see Tatto et al., 2008, p. 36). The tasks fall within topics of mathematics that are taught in lower secondary school, but topics from higher level (upper secondary and university) are also included (see Table 1).

Table 1. Content knowledge domains in the TEDS-M test

\begin{tabular}{cccc}
\hline Numbers & Geometry & Algebra & Data \\
\hline Whole numbers & Geometric shapes & Patterns & Data organization and \\
Fractions and decimals & Geometric & Algebraic expressions & represtation \\
Number sentences & measurement & Equations/formulas & Data reading and \\
and functions & interpretation \\
relationships & Location and & Chance \\
Integers & movement & Calculus and analysis & Linear algebra and \\
Ratios, proportions, & & abstract algebra & \\
and percent & & & \\
Irrational numbers & & & \\
Number theory & & & \\
\hline
\end{tabular}

Source: TEDS-M Conceptual Framework (Tatoo et al., 2008)

The cognitive domains also follow the TIMMS framework, covering three main components: knowing, applying, and reasoning. Tables 1 and 2present the topics and skills included in the content and cognitive domain, respectively. 
Table 2. Cognitive domains in the TEDS-M test

\begin{tabular}{ccc}
\hline Knowing & Applying & Reasoning \\
\hline $\begin{array}{c}\text { Recall, recognize, compute, } \\
\text { retrieve, measure, classify/ } \\
\text { order }\end{array}$ & Select, represent, model, & Analyze, generalize, \\
implement, solve routine & problems & synthesize/integrate, justify, \\
solve non-routine problems
\end{tabular}

Source: TEDS-M Conceptual Framework (Tatoo et al., 2008)

Mathematical pedagogical content knowledge (MPCK): For the TEDS-M framework, the MPCK includes all the knowledge about teaching and learning mathematics. It also includes what Shulman called "curricular knowledge", namely the order of topics and the connections between them, as well as the curricular requirements (Blömeke, 2012). Hence, this construct focuses on "the temporal dimension of teaching, moving from what mathematics to teach, to planning to teach it, to carrying out instruction" (Senk et al., 2008, p. 5). In the TEDS-M framework, the MPCK has three sub-domains: mathematics curricular knowledge, knowledge of planning mathematics, and knowledge of enacting mathematics. The descriptions of each are presented in Table 3. In the MPCK test items, the first two sub-domains are combined.

Table 3. Mathematical pedagogical content knowledge sub-domains

\begin{tabular}{|c|c|c|}
\hline $\begin{array}{c}\text { Mathematics curricular } \\
\text { knowledge }\end{array}$ & $\begin{array}{c}\text { Knowledge of planning for } \\
\text { mathematics teaching and } \\
\text { learning }\end{array}$ & $\begin{array}{l}\text { Enacting mathematics for } \\
\text { mathematics teaching and } \\
\text { learning }\end{array}$ \\
\hline $\begin{array}{l}\text {-Establishing appropriate } \\
\text { learning goals } \\
\text {-Knowing different assessment } \\
\text { formats } \\
\text {-Selecting possible pathways } \\
\text { and seeing connections within } \\
\text { the curriculum } \\
\text {-Identifying the key ideas in } \\
\text { learning programs } \\
\text {-Knowledge of mathematics } \\
\text { curriculum }\end{array}$ & $\begin{array}{l}\text {-Planning or selecting } \\
\text { appropriate activities } \\
\text {-Choosing assessment formats } \\
\text {-Predicting typical students' } \\
\text { responses, including } \\
\text { misconceptions } \\
\text {-Planning appropriate methods } \\
\text { for representing mathematical } \\
\text { ideas } \\
\text {-Linking didactic methods and } \\
\text { instructional designs } \\
\text {-Identifying different } \\
\text { approaches for solving } \\
\text { mathematical problems } \\
\text {-Planning mathematics lessons }\end{array}$ & $\begin{array}{l}\text {-Analyzing or evaluating } \\
\text { students' mathematical } \\
\text { solutions or arguments } \\
\text {-Analyzing the content of } \\
\text { students' questions } \\
\text {-Diagnosing typical students' } \\
\text { responses, including } \\
\text { misconceptions } \\
\text {-Explaining or representing } \\
\text { mathematical concepts or } \\
\text { procedures } \\
\text {-Generating fruitful questions } \\
\text {-Responding to unexpected } \\
\text { mathematical issues } \\
\text {-Providing appropriate } \\
\text { feedback }\end{array}$ \\
\hline
\end{tabular}

Source: TEDS-M Conceptual Framework (Tatoo et al., 2008)

In light of our interest in the opportunities to learn that have an impact on teacher outcomes and the questionnaire for investigating future teachers' mathematical content and pedagogical knowledge, this research aims to answer the following questions:

1. What are the opportunities to learn offered in Costa Rican mathematics teacher education programs?

a) How are the OTL distributed in the knowledge areas?

2. How do trainee mathematics teachers perform in the teaching items in the area of mathematical knowledge?

a) How do they perform in mathematical content knowledge and cognitive domains items? 
b) How do they perform in mathematical pedagogical content knowledge and sub-domains items?

3. How are learning opportunities and the performance of future teachers related in the Costa Rican context?

\section{Methods}

\section{Context}

In Costa Rica, eight universities offer a major in teaching mathematics. Graduates from these majors can teach grades seven to 11 or become university teachers of basic math courses for non-mathematics majors. The teacher education programs (TEPs) in Costa Rica are delivered concurrently (Tatoo et al, 2008), meaning that they comprise mathematics courses, general education courses, and mathematics education courses in the same program. Neither the government nor the ministry of education sets any standards or stipulations for the universities to design their TEPs. Hence, each university designs its program according to what it believes teachers need to learn and for the context. Consequently, the TEPs vary between universities in content, duration, and quality (Román \& Lentini, 2018). A TEP leading to a bachelor's degree at a private university takes two and a half years, whereas programs at public universities take four years for a bachelor's degree and five years for a licenciate. Recruitment in Costa Rica does not take account of these differences, the only requirement being that an applicant must have a teaching degree. The ministry of public education is the principal hiring entity, and in the hiring process the teachers are not interviewed or assessed in content knowledge or pedagogical skills (Román \& Lentini, 2018). Nor is there a mechanism to filter students entering education careers. Teaching is generally considered tiring and the workload is very high. However, in some cases, teachers are willing to pay the price in exchange for the job security offered by public positions.

\section{Sample}

The subjects in this study were Costa Rican pre-service mathematics teachers. There are eight institutions in the country that prepare mathematics teachers, and all were invited to participate. Five public universities agreed to be part of the study; however, one offered only distance learning, so the data collection was not possible with that population. Hence, the sample consisted of 80 pre-service mathematics teachers from four public universities in Costa Rica. The participants were at the end of their studies, in either the fourth or the fifth year of their teaching program. The average age of the future teachers was 23.8 years $(\mathrm{SD}=2.89)$, and $44(\mathrm{~N}=80)$ of them were male. The questionnaire was administered in seven groups, as described in Table 4. Participation was voluntary, and the participants were informed that their performance on the test would be not considered in their grades. The data were collected in the autumn of 2019, with a pencil-and-paper questionnaire. The students had a maximum of three hours to do the questionnaire.

Table 4. Distribution of the participants by university

\begin{tabular}{|c|c|c|}
\hline University & Number of groups & Number of participants \\
\hline A & 2 & 24 \\
\hline B & 1 & 8 \\
\hline $\mathrm{C}$ & 2 & 19 \\
\hline $\mathrm{D}$ & 2 & 29 \\
\hline Total & 7 & 80 \\
\hline
\end{tabular}

\section{Instrument}

The instrument for collecting the data was the questionnaire used in the TEDS-M study from the IEA. With permission from the IEA, the first author translated the documents into Spanish. After the translation and contextualization of the questionnaire, two mathematics education researchers and one 
university mathematics teacher were asked to proofread the questionnaire in order to check the language and comprehensibility of the items, as well as the suitability of the context. Improvements for the questionnaire were made based on the comments. All the collaborators were Spanish speakers and outsiders to the research. The international reliability of the TEDS-M questionnaire scales ranges from 0.78 to 0.97 , and the items have been internationally tried and examined by expert panels (Tatoo et al., 2008).

The questionnaire consisted of three parts: students' background, opportunities to learn (OTL), and the test of mathematics content knowledge (MCK) and mathematical pedagogical content knowledge (MPCK). A further question was added at the end of the questionnaire, asking the students which knowledge area they thought was necessary to make their TEP more relevant. The first part of the questionnaire included questions regarding the participants' background, for instance, parents' education level and students' previous mathematics level. The second part had questions about the OTL the participants had in their teaching programs, with answers ranked on Likert scales. This section included questions about the courses they had, how they took part in them, and what skills they learned related to their profession. In the section on OTL, there were three types of questions, as described in Table 5. The OTL covered tertiary level and school mathematics topics, as well as topics of general pedagogy and mathematics education pedagogy. In addition, questions were asked about the teaching practices the participants experienced at university and about the opportunities they had to engage in activities for improving and reflecting on their practice, or learning how to deal with and value diversity in the classroom. Finally, it involved questions about the participants' practical experience in school and their perception of the program's coherence.

Table 5. Types of questions to be rated on Likert scales (statements from TEDS-M questionnaire) \begin{tabular}{l|l} 
Type 1 & Consider the following topics in university-level mathematics. Please indicate whether
\end{tabular}

\begin{tabular}{|c|c|c|} 
& G. Set theory & you have ever studied each topic. \\
Type 2 & $\begin{array}{c}\text { In the mathematics education courses that you have taken or are currently taking in } \\
\text { your teacher preparation program, how frequently did you do/engage in activities that } \\
\text { gave you the opportunity to do the following? } \\
\text { (Never, rarely, occasionally, often) } \\
\text { L. Write mathematical proofs }\end{array}$ \\
\hline Type 3 & $\begin{array}{c}\text { To what extent do you agree or disagree with the following statements about the field } \\
\text { experience you had in your teacher preparation program? } \\
\text { D. I learned the same criteria or standards for good teaching in my courses and my } \\
\text { (Disagree, slightly disagree, slightly agree, agree) }\end{array}$ \\
\hline
\end{tabular}

The last part of the questionnaire consisted of mathematics tasks to assess the participants' mathematical content knowledge and mathematical pedagogical content knowledge. The students were presented with 13 tasks, divided into 31 items, on different mathematics topics. There were 22 items relating to MCK and nine relating to MPCK. Those tasks corresponded to the released items of the TEDS-M test (see Brese \& Tatto, 2012) and concentrated on the mathematics taught at secondary level in the Costa Rican context and some topics taught at university level. The item distribution is shown in Table 6.

Table 6. Distribution of the TEDS- M released items used in the test

\begin{tabular}{ccccccc}
\hline & \multicolumn{2}{c}{$\begin{array}{c}\text { Mathematical content knowledge } \\
\text { Cognitive domains }\end{array}$} & & \multicolumn{2}{c}{$\begin{array}{c}\text { Mathematical pedagogical content knowledge } \\
\text { Sub-domains }\end{array}$} \\
\cline { 2 - 3 } domains & Applying & Knowing & Reasoning & & $\begin{array}{c}\text { Implementing } \\
\text { Teaching \&Learning }\end{array}$ & Curriculum \& planning \\
\hline Numbers & - & 4 & 4 & & 3 & - \\
Geometry & 4 & 2 & - & & - & - \\
Algebra & 5 & - & 2 & & 1 & 4 \\
Data & 1 & - & - & & 1 & - \\
\hline
\end{tabular}


To complete the entire questionnaire, the participants were allowed one session, taking as much time they considered necessary up to a maximum of three hours. The TEDS-M international study indicates that the participants should have 90 minutes for completing the questionnaire, but, owing to sample limitations, we decided to give more time to reduce the likelihood of missing data. The questions did not vary within tests as in the original study; in this case, all the participants answered the same tasks. Therefore, as there are some differences in application and format between this study and the one carried out by the IEA, comparisons should be made with caution.

\section{Analysis}

The data were analyzed using quantitative methods, such as descriptive statistics and non-parametric statistical tests. Before the analysis, the data were cleaned and the missing data for the latent variables in the Likert scales were handled using median imputation. For the school practice scales, the cases of the participants who had not yet taken part in that practice experience were not counted. The scales with type 1 questions were analyzed by adding the studied topics and computing the percentage of studied topics in each OTL category. This means that, of the 19 tertiary-level mathematics topics presented, we calculated the percentage of studied topics the students reported. The comparison between categories and TEPs was easier to make by percentage. Type 2 and 3 group scales were computed using the mean. The tasks in part three were evaluated according to the coding provided in the TEDS-M supplement 4 (Brese \& Tatoo, 2012), and the results were obtained by computing the percentage of correct answers out of the totality of the tasks, by MKC and MPCK, by knowledge area, and by cognitive domain.

\section{Results}

In this section, we present the results relating to the mathematical knowledge for teaching that is intended and achieved by future teachers in Costa Rica at the end of their TEPs. First, we describe the OTL they were exposed to; next, we present the results of the future teachers' performance on the MCK and MPCK tasks; and finally, we discuss the correlations found between the OTL and the test results.

\section{Opportunities to learn (OTL)}

Investigating the OTL to which the future teachers are exposed during their TEPs is crucial for analyzing the quality of their training, as well as for understanding their performance on the test. The participants were asked to report on their OTL in categories that would be assumed to enhance their mathematical knowledge for teaching (Tatto et al., 2012). The categories were: 1) tertiary-level mathematics, 2) school-level mathematics, 3) general pedagogy, 4) mathematics education pedagogy (academic content and teaching methods), 5) teaching diverse students, 6) reflecting and improving practice, 7) learning through school-based experience, and 8) the coherence of the TEP. The results for each category are described in the following section. 
1 Opportunities to learn tertiary-level mathematics topics: In this category, the questions are type 1. In total there are 19 tertiary-level topics, divided into six knowledge areas: geometry (4), discrete structures and logic (6), continuity and functions (5), probability and statistics (2), topology (1), and theory of real and/or complex functions (1). Each statement refers to a general topic and presents examples of what could be included in that topic, enabling the participants to choose. For instance, one statement is "Linear algebra (e.g., vector spaces, matrices, dimensions, eigenvalues, eigenvectors)." The results show that the participants had studied on average $78.4 \%$ of the tertiary-level mathematics topics presented, with some variability among universities. Table 7 indicates the mean number and average percentage of tertiary-level math topics per university, showing that University C covered the largest number of courses in this area and University D the fewest. Thus, the TEPs vary and each institution has a different view of the number of mathematics topics required for mathematics teachers, considering the limited time for training.

Table 7. Mean number and average percentage of the 19 topics studied in tertiary-level mathematics,

\begin{tabular}{cccc}
\hline University & $\begin{array}{c}\text { Number of } \\
\text { future teachers }\end{array}$ & $\begin{array}{c}\text { Mean number of } \\
\text { topics }\end{array}$ & $\begin{array}{c}\text { Average \% of } \\
\text { topics }\end{array}$ \\
\hline A & 24 & 15.1 & 79.4 \\
B & 8 & 15.1 & 79.4 \\
C & 19 & 16.4 & 86.3 \\
D & 29 & 13.7 & 72.1 \\
Composite results & & $\mathbf{1 4 . 9}$ & $\mathbf{7 8 . 4}$ \\
\hline
\end{tabular}

The OTL can also be analyzed by mathematics content. Here, the results show that future teachers studied a higher number of structure- and logic-related courses ( 5.2 out of 6 ), followed by the continuity and functions area (3.9 out of 5). The areas with fewer topics were geometry (2.9 out of 4 ) and probability and statistics (1.9 out of 2 ). The focus on the areas of structure and logic and continuity and functions is consistent with the Costa Rican mathematics school curriculum for secondary level (MEP, 2012), in which algebra and relations occupy more time and topics. However, in the second topic of importance in the school curriculum, statistics and probability, future teachers studied only two topics. On the other hand, future teachers were trained in more areas than are strictly necessary for teaching in secondary schools, such as calculus, logic, differential equations, and number theory. The knowledge in these areas supports teaching in secondary schools and gives teachers the tools they need if they decide to teach in another environment, such as a university or institute, as stated in the professional profile of some TEPs.

2 Opportunities to learn school mathematics topics: The questions in this category are type 1 and ask the participants whether they have studied the seven school-level math topics. These topics are divided into two content areas, the numbers, measurement, and geometry area (3 questions) and the functions, probability, and calculus area (4 questions). The topics described as school-level are topics that the future teachers will teach in secondary school. The results for this category showed that $93 \%(\mathrm{SD}=12.7)$ of the given topics were studied in the TEPs. This indicates that the participants from all the TEPs studied at least six of the seven topics. The variation between universities was very small; nevertheless, University A and University C reported higher numbers (6.6 and 6.7, respectively) than University B and University D (both 6.3). 
3 Opportunities to learn general pedagogy: Questions in this category explore whether the courses the participants studied had covered the following eight topics: the history of education and education systems, philosophy of education, sociology of education, educational psychology, theories of schooling, methods of educational research, assessment and measurement, and knowledge of teaching. The results presented in Table 8 show that the participants studied on average 5.8 of the eight topics related to educational pedagogy. The figures for Universities A, B, and C were very similar, but a smaller number of topics was covered at University D.

Table 8. Mean number and average percentage of the eight topics studied in general pedagogy, by

\begin{tabular}{cccc}
\hline University & $\begin{array}{c}\text { Number of } \\
\text { future teachers }\end{array}$ & $\begin{array}{c}\text { Mean number of } \\
\text { topics }\end{array}$ & $\begin{array}{c}\text { Average \% of } \\
\text { topics }\end{array}$ \\
\hline A & 24 & 6.2 & 77 \\
B & 8 & 6.3 & 78 \\
C & 19 & 6.1 & 76 \\
D & 29 & 5.3 & 66 \\
Composite results & & 5.8 & 73
\end{tabular}

4 Opportunities to learn mathematics education pedagogy topics: There are two areas of interest in this category: the academic content and the teaching methods experienced. Eight topics are related to academic content, namely foundations of mathematics, the context of mathematics education, development of mathematics ability and thinking, mathematics instruction, development of teaching plans, mathematics teaching, mathematics standards and curriculum, and affective issues in mathematics. The results presented in Table 9 show that the TEPs covered on average 5.6 out of the eight topics, although there was high variability among the universities. For example, while Universities A and B covered approximately four topics, University C covered 5.9 and University D covered 6.8 of the topics. This again highlights the variation among TEPs in Costa Rica.

Table 9. Mean number and average percentage of the eight topics studied in mathematics pedagogy, by university

\begin{tabular}{cccc}
\hline University & $\begin{array}{c}\text { Number of } \\
\text { future teachers }\end{array}$ & $\begin{array}{c}\text { Mean number of } \\
\text { topics }\end{array}$ & $\begin{array}{c}\text { Average \% of } \\
\text { topics }\end{array}$ \\
\hline A & 24 & 4.4 & 55 \\
B & 8 & 4.0 & 50 \\
C & 19 & 5.9 & 74 \\
D & 29 & 6.8 & 85 \\
Composite result & & 5.6 & 70 \\
\hline
\end{tabular}

At this stage, it is important to note that the TEP of Universities A and B is the same but is delivered on different campuses. Nevertheless, both universities showed a deficit in this area. In addition, it should be noted that, at University $\mathrm{D}$, mathematics education is the only teaching major they offer; therefore, the courses are subject-focused, whereas, in the other universities, some education courses are shared with other subject majors. This could explain why University D offers significantly more topics in this area than the other universities.

The teaching methods experienced were measured with type 2 questions using Likert scale rankings for the answers. The questions asked how often the participants had the opportunity to practice or learn a specific activity. In this section, the statements included the teaching methods typically employed in university programs, such as "listen to a lecture," and those specific to mathematics programs, such as "write mathematical proofs." The section also covers the methods important for teaching practice in 
areas such as instruction and assessment and those that support the role of teacher as researcher. Figure 1 shows the average frequency with which participants reportedly experienced the activities mentioned. Overall, $63 \%$ of the participants read papers related to mathematics education occasionally or frequently and $67 \%$ had the opportunity to ask questions, participate in discussions, make presentations, or teach class sessions, all forms of active participation in their classes. Moreover, future teachers had the chance to practice their problem-solving skills occasionally $(32 \%)$ or frequently $(34 \%)$. These results demonstrate that the class activities were varied, and the time spent balanced between class participation, class reading and solving problems.

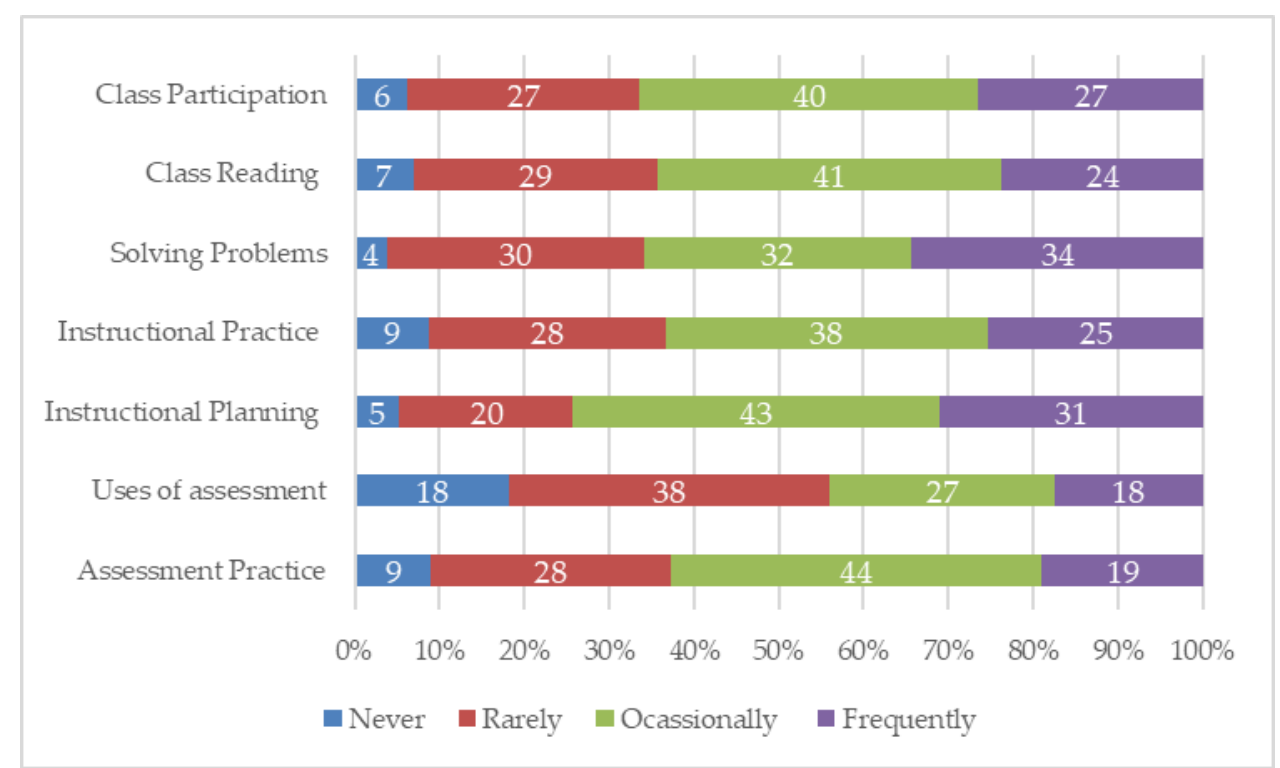

Figure 1. Frequency of experiencing teaching methods ( $\mathrm{N}$ of students $=80$ ).

Most of the students reported that they occasionally or frequently had the opportunity to learn or practice assessment and instruction activities, except those related to the uses of assessment, which was rarely practiced $(38 \%)$. This means they did not have enough practice in using feedback to enhance their students' (and parents') learning or their own teaching. However, as shown in Figure 1, the participants reported having occasionally (44\%) or frequently (19\%) practiced their assessment skills in practical tasks such as devising exams and evaluating the attainment of learning goals.

Asked to what extent the future teachers took part in instruction planning activities, $74 \%$ said they had done so occasionally or more often. This suggests that the TEPs are giving the participants good opportunities to learn to plan and design classes, taking into consideration time, motivation, and learning difficulties. The practice of instruction covers the topics of integrating mathematical ideas, showing different procedures for solving tasks, and giving explanations. For this section, the participants reported having had the opportunity to practice it occasionally $(38 \%)$ or frequently $(25 \%)$. Experimenting with different teaching methods provided the future teachers with a strong body of resources to support good teaching practice.

5 OTL about teaching diverse students: This scale measures how frequently the students were trained in teaching students with diverse needs, notably those from racial, cultural, and linguistic minorities, those with learning or physical disabilities or behavioral problems, and the gifted and talented. Most of the future teachers (67\%) were rarely or never exposed to these topics in their TEPs, suggesting that they lack the necessary knowledge for teaching such students. Only $23 \%$ of the participants reported occasionally or frequently learning strategies for teaching pupils from a minority cultural background. The TEPs in Costa Rica that cover diversity usually focus on pupils with learning and physical disabilities. In their responses to statements, the future teachers reported occasionally $(43 \%)$ or 
frequently (39\%) learning about these topics. The infrequency with which diversity issues are discussed in the TEPs is undoubtedly worrying.

6 OTL for reflecting and improving practice: In their teaching practice, teachers must have the time and tools to reflect on their practices and continuously try to find ways of improving them. This category explores how often the participants had the opportunity to learn how to do so. Among the activities covered are the development of strategies to reflect on their teaching effectiveness and professional knowledge, and to identify their learning needs. In this regard, $60 \%$ of the participants answered that they never or rarely had the opportunity to learn such strategies. Also, they were asked how often they participated in activities for learning to enhance their practice, such as "developing and testing new teaching practices." The results suggest that $55 \%$ of the future teachers never or rarely participated in such activities in their TEP.

7 OTL through school-based experience: The questionnaire also investigates the experiences the participants had of practice teaching in schools. Although all the TEPs involved in this research included school-based practice, only $73.8 \%(\mathrm{~N}=80)$ of the participants had already done so. Asked how often the knowledge about teaching they learned at university was applied in their practice, future teachers' answers included occasionally $(28.2 \%)$ and frequently $(26.5 \%)$. They were also asked about the extent to which the role of supervisor in giving feedback complied with the university's goals. Most of the students agreed $(74.2 \%)$ that the comments they got from their supervisor helped them to improve their teaching methods, their understanding of their pupils and the curriculum, and their mathematics content knowledge. Hence, the feedback was positive in terms of improving their teaching performance. Concerning the supervisor's reinforcement of the university's goals for practice, $78.3 \%$ of the participants affirmed that the actions and knowledge they gained during their teaching practice aligned with what they had learned during their university course.

8 OTL in a coherent program: Participants were asked about the connections between the courses they studied and if they seemed to have been organized logically and functionally, allowing the participant to learn what they needed to learn to become effective teachers, and met the expected standards. Slight agreement with the statement that the program was coherent was reported by $40 \%$ of the students $(\mathrm{N}$ $=80$ ). Greater agreement was shown by the participants from University D, of whom $86 \%$ reported slight or total agreement (see Figure 2). By contrast, $48 \%$ of participants from University A disagreed or slightly disagreed with the statement about the coherence of their program.

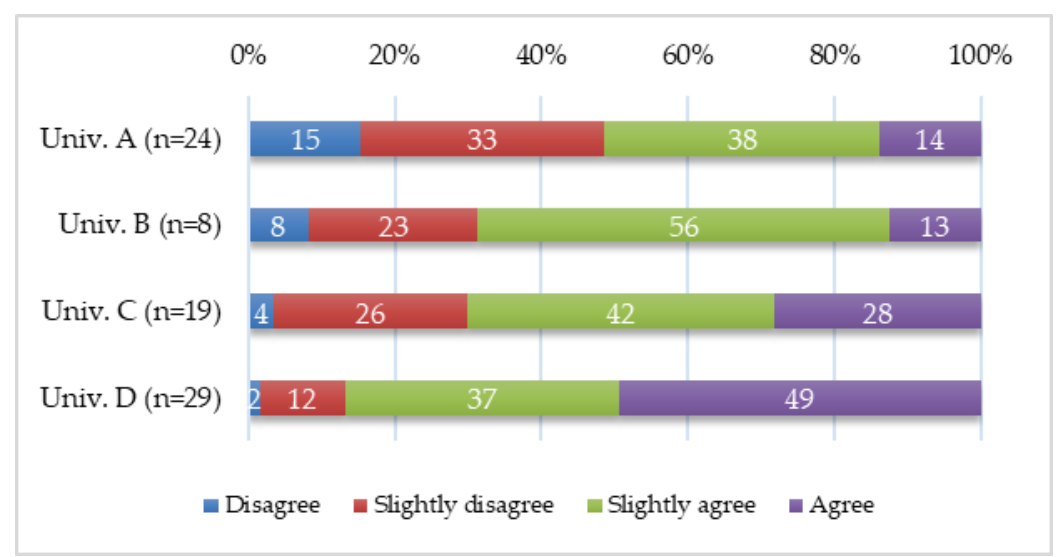

Figure 2. Participants' agreement with the statement that their program was coherent.

In order to gain more precise information about how the future teachers felt about their TEP, they were asked to select which, if any, area of their TEP needed to be supplemented with more courses. There 
were five options, from which they could choose more than one. Most of the participants responded that more courses were needed in mathematics education, as shown in Figure 3. A majority also considered that their TEPs should offer more opportunities for practice teaching.

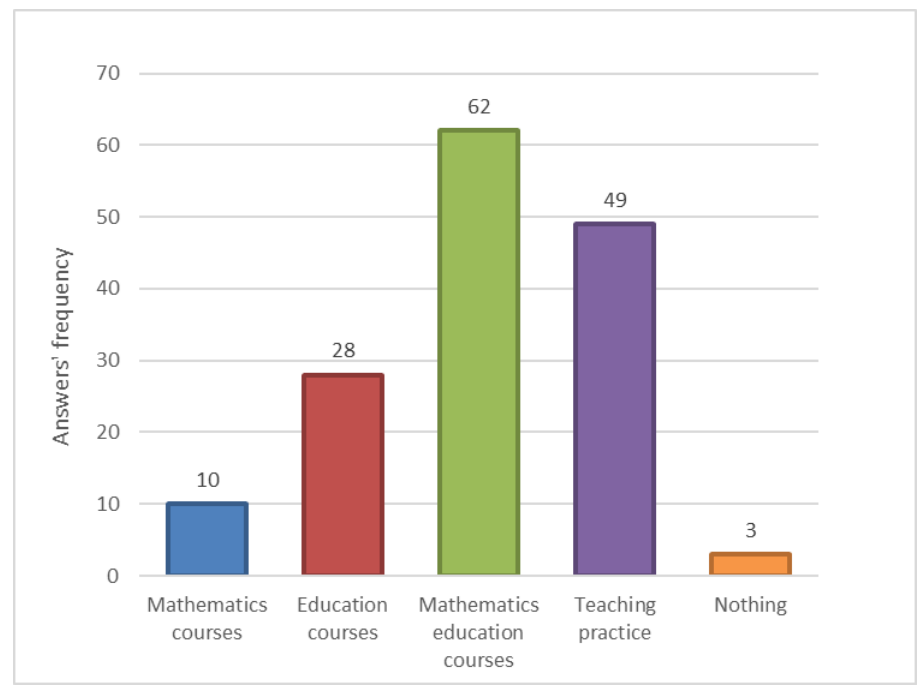

Figure 3. Courses that trainee teachers felt should be added to their TEP.

Mathematical content knowledge (MCK) and mathematical pedagogical content knowledge (MPCK) tasks In addition to responding to the questionnaire, the participants were asked to undertake 13 mathematical tasks relating to knowledge for teaching mathematics. The tasks were grouped according to the theoretical constructs of MCK and MPCK and assessed mathematics content knowledge, cognitive domains, and skills. In total, there were 31 questions, 22 about MCK and nine about MPCK. The MCK tasks were categorized by content knowledge and cognitive domain, and the MPCK were classified by content area and teaching knowledge.

Considering the two constructs, the results showed that the participants were able to answer $66.9 \%$ of the MCK questions and $79.2 \%$ of the MPCK correctly. The results are analyzed separately in the following.

Mathematical content knowledge tasks: There were four content knowledge domains involved: numbers, geometry, algebra, and data. The task of each content knowledge domain was classified according to the cognitive domains of applying, knowing, and reasoning, as shown in Table 3. In geometry, participants answered $63.8 \%$ of the questions correctly, with a better performance in the applying (66.4\%) domain than in the knowing domain (58.8\%). In algebra, $67.0 \%$ of the items were answered correctly, although there were differences in performance between exercises in applying knowledge $(70.3 \%)$ and reasoning $(58.8 \%)$. Regarding the numbers domain, the participants answered $66.9 \%$ of the eight exercises on the knowing and reasoning domains correctly, with performances of $68.1 \%$ and $65.6 \%$, respectively. Finally, the data exercise in the applying domain was solved correctly by $85 \%$ of the participants; however, as it consisted of only one question, the number is not representative. In all, the results demonstrate that the students' performance was better in the algebra cognitive domain, excluding the single data exercise. Moreover, they did better on the exercises in the applying domain, with $70.1 \%$ correct answers, compared with $65 \%$ in knowing and $63.3 \%$ in reasoning (see Table 10). According to the framework used in the TEDS-M study, these results suggest that trainee teachers are better at selecting, representing, modeling, implementing, and solving routine problems than in the knowledge skills of recall, recognize, compute, measure, or order and in the reasoning skills of analyze, generalize, integrate, justify, and solve non-routine problems. 
Table 10. Percentage of correct answers in the mathematical content knowledge exercises

\begin{tabular}{|c|c|c|c|c|c|}
\hline MCK & Numbers \% & Geometry\% & Algebra \% & Data \% & $\begin{array}{c}\text { General } \\
\text { average } \%\end{array}$ \\
\hline Applying & - & 66.2 & 70.2 & 85 & 70.1 \\
\hline Knowing & 68.1 & 58.8 & - & - & 65 \\
\hline Reasoning & 65.6 & - & 58.8 & - & 63.3 \\
\hline $\begin{array}{l}\text { General } \\
\text { average }\end{array}$ & 66.9 & 63.8 & 67 & 85 & \\
\hline
\end{tabular}

Mathematical pedagogical content knowledge tasks: The exercises in MPCK assess teaching skills, as well as abilities in curriculum and planning. The participants were asked to solve questions about algebra, numbers, and data. It was found that $79.2 \%$ of the students correctly solved the numbers exercises, $76.3 \%$ the data task, and $79.8 \%$ the algebra tasks. In the teaching and learning domain, $76.8 \%$ of the participants answered correctly, and $82.2 \%$ gave valid answers to the curriculum and planning tasks. Although there was no big difference between the results, the content knowledge area of algebra received the highest number of correct answers. With regard to teaching knowledge, the participants showed better performance in the curriculum and planning domain.

Correlation between the topics studied and the test results

Considering OTL tertiary and school-level mathematics topics and topics in mathematics education pedagogy in the TEPs, as well as the results of the exercises, we ran statistical tests to determine if there was a correlation between OTL offered in the TEPs and the students' performance in the exercises.

First, we analyzed if there were performance differences among universities. A Kruskal-Wallis $\mathrm{H}$ test showed that there was a statistically significant difference in the distribution of the total correct answers between universities, $(\chi 2(3)=17.079, p \leq 0.001)$. Further analysis showed that the distribution of MPCK correct answers was the same across universities, but there was a significant difference in the correct answers on MCK items, $(\chi 2(3)=17.084, p \leq 0.001)$. The plot in Figure 4 presents the distribution of the percentage of correct answers for each university. In both constructs, participants from University A performed better, with half of the participants obtaining $80 \%$ or more correct answers. Participants from Universities B and D had the lowest performance in the MCK tasks, more than half of the participants answering less than $60 \%$ of the tasks correctly. 


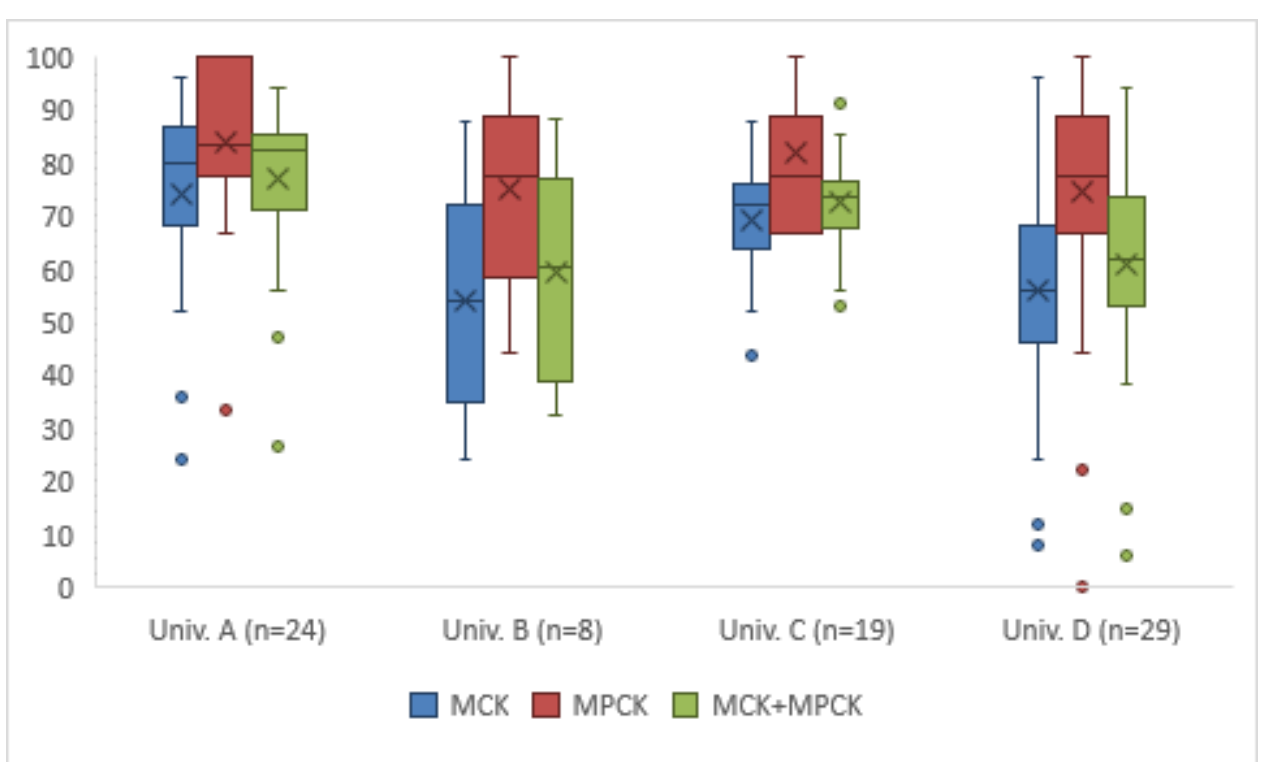

Figure 4. Future teachers' performance on the MCK and MPCK items, by university.

Considering the results of previous studies linking performance on the test with the number of topics studied (e.g., Schmidt et al., 2011b; Qian \& Youngs, 2016), we then analyzed the weight that was given to each area in the TEPs. The distribution was analyzed in the areas of general education pedagogy, mathematics, and mathematics education pedagogy. School mathematics was included in mathematics education pedagogy. In general, the TEPs in Costa Rica covered 33 of the 42 topics in the questionnaire. The mathematics topics represented $45 \%$, mathematics education pedagogy $37 \%$, and general education pedagogy only $18 \%$. Table 11 shows how the topics were distributed in each area in the four universities involved. University D covered more topics related to mathematics education, but fewer related to mathematics and education pedagogy. The results for Universities A and B were consistent, given that they share the same TEP but taught at different campuses. On the other hand, University C had the highest number of courses in mathematics and offered a large number of courses in mathematics education pedagogy, general pedagogy being the area with less emphasis.

Table 11. Mean number and percentage of topics studied, by university

\begin{tabular}{ccccccccc}
\hline \multirow{2}{*}{ University } & \multicolumn{2}{c}{ Mathematics } & & \multicolumn{2}{c}{$\begin{array}{c}\text { Mathematics } \\
\text { education pedagogy }\end{array}$} & & \multicolumn{2}{c}{$\begin{array}{c}\text { General education } \\
\text { pedagogy }\end{array}$} \\
\cline { 2 - 3 } & Mean & $\%$ & & Mean & $\%$ & & Mean & $\%$ \\
\hline Univ. A & 15.1 & 47 & & 11 & 34 & & 6.2 & 19 \\
Univ. B & 15.1 & 48 & & 10.3 & 32 & & 6.3 & 20 \\
Univ. C & 16.4 & 47 & & 12.7 & 36 & & 6.1 & 17 \\
Univ. D & 13.7 & 43 & & 13.1 & 41 & & 5.3 & 16 \\
Composite results & $\mathbf{1 4 . 9}$ & $\mathbf{4 5}$ & & $\mathbf{1 2 . 1}$ & $\mathbf{3 7}$ & & $\mathbf{5 . 8}$ & $\mathbf{1 8}$ \\
\hline
\end{tabular}

From the performance in the MCK and MPCK items and the details of topics studied in each TEP, shown in Table 11, it may be seen that the performance do not seem to be associated with the extent to which the future teachers have studied topics related to MCK or MPCK. For instance, although Universities $A$ and $C$ have fewer topics of mathematics education pedagogy in their program than University D, the participants from the first two had a better performance in the MPCK test. Similarly, students from University A gained the best results in the MCK items, despite studying the same number of mathematics topics as University B and fewer than University C. This assumption is supported by a Spearman's analysis of correlation assessing the relationship between the numbers of MCK correct answers and the number of topics studied, which found no significant correlation between 
these categories. The same analysis conducted on the number of MPCK correct answers and the MPCK topics studied again found no significant correlation.

Similarly, we examined if there were correlations between the knowledge areas of the mathematical topics (geometry, discrete structures and logic, continuity and functions, and probability and statistics) and the MCK grade. Spearman's analysis of correlation found that only the probability and statistics area had a positive correlation $(r s=0.235, N=80, p \leq 0.05)$ with the MCK grade. The other three areas did not show any significant correlation. Using the Spearman's test again, we also explored whether there was correlation between MPCK knowledge and the OTL of the teaching methods experienced; no significant correlation was found.

\section{Discussion}

As the literature confirms, opportunities to learn and the quality of TEPs have an important effect on students' performance. This study aimed to identify the structure of four Costa Rican mathematics teacher education programs, exploring the opportunities to learn in the courses and teaching experiences offered to 80 future teachers in the last year of their TEP. Using MCK and MPCK items, we studied the performance of the participants in mathematical knowledge. The OTL and the test results allowed us to investigate possible correlations and analyze the possible consequences of large variations in the quality and offer of TEPs. As an additional feature, we used the TEDS-M international results to compare Costa Rican TEPs with those designed for lower secondary and higher secondary (Groups 5 and 6; see Tatoo et al., 2012) teaching in countries rated top-achieving or A+ (i.e., Taiwan, Russian Federation, Singapore, and Poland, according to Smith et al., 2011a), and the countries closer to Costa Rican region, the United States and Chile.

The OTL were used to describe the structure of the TEPs. The courses taken in the three areas of mathematics, mathematics education pedagogy, and general education pedagogy were considered. The results showed that in the TEPs the emphasis was on tertiary-level mathematics courses, which represented $45 \%$ of all the topics studied. Of the 19 topics mentioned, Costa Rican future teachers studied 14.9. According to the TEDS-M results, the TEPs in Costa Rica thus cover more tertiary-level mathematics topics than Chile with 10.3 (Tatto et al., 2012) and the United States with 9.5, while A+ countries offer on average 17.1 (Schmidt et al., 2011a). Thus, on average, future teachers in Costa Rica have access to only two fewer mathematics courses than the top-achieving countries.

The TEPs in Costa Rica dedicate $18 \%$ of the topics to general education pedagogy, which makes it the area with the fewest topics. For this area, the programs include on average 5.8 topics, in contrast with 7 in Chile (Tatto et al., 2012), 6.7 in the US, and 6.6 in the A+ countries (Schmidt et al., 2011a). This places the TEPs in Costa Rica toward the bottom of the list of countries mentioned for number of topics in this area. On the other hand, the TEPs allocate $37 \%$ of the courses to the mathematics education pedagogy area, covering 12.1 related topics. The number of topics covered by the A+ countries is 11.8 , by the US 11.3, and by Chile 9.4 (Tatto et al., 2012). Thus, in Costa Rica, the TEPs focus on the mathematics pedagogy topics more than the other countries. In conclusion, the TEPs in Costa Rica devote $45 \%$ of their courses to mathematics, 37\% to mathematics pedagogy, and $18 \%$ to general pedagogy. By contrast, the two top-achieving countries, Taiwan and Russia, dedicate approximately $50 \%, 30 \%$, and $20 \%$ to the three areas, respectively, the figures for the US being 40\%,30\%, and 30\%, respectively (Schmidt et al., 2011b). Hence, the percentages by which mathematics and general pedagogy in the Costa Rican TEPs undershoot the top-achieving countries are allocated to mathematics education pedagogy, which suggests that the future teachers have more OTL in this area than the rest.

Interestingly, when the participants were asked in which area they thought there should be more courses in their TEPs, the majority suggested mathematics education. These results align with the 
findings of a similar study in Finland, in which practicing teachers demanded more courses on "teaching mathematics, students' learning difficulties, and how to differentiate mathematics teaching" (Koponen et al., 2016, p. 165). The need for more mathematics pedagogy courses may respond to the historical dissociation between courses with mathematical and pedagogical content in Costa Rican universities (Alfaro et al., 2013). However, this disconnect also occurs in other contexts (e.g., Koponen et al., 2016) and risks impacting on the quality of mathematics education because it is translated into teaching practice. Another possible reason why the future teachers feel they need more support in mathematics education topics could be the quality and specificity of the courses in this area. Further research will be needed to determine the facts of this issue.

Another significant finding related to the structure of TEPs is the variability in the distribution of the topics in the three areas in each university. For instance, Universities C and D include on average two more topics in mathematics education pedagogy than the others, whereas the difference between these two universities in the mathematics topics is around three. Therefore, the training offered varies from one university to the next, and, according to Blömeke (2012), this responds to the fact that each institution has its vision of what teachers must know and do to be good teachers, as well as the organization of teacher training. Moreover, the outcomes also show variability in the distribution of the correct answers supplied by the future teachers, which, in the case of participants from Universities B and $\mathrm{D}$, amounted to only $50 \%$ of the MCK items. Hence, considering the lack of national strategies to assess the quality of teachers before and during service (Román \& Lentini, 2018), policymakers and the government, being the main entity for teacher recruitment, should review the variations among the TEPs to ensure that all programs provide appropriate and high-quality training. As has been mentioned, the quality of teacher education influences the quality of education that pupils receive (Hill, et al., 2005).

The analysis of the OTL related to the teaching methods experienced revealed some strengths and weaknesses of the TEPs. For instance, a positive result is that future teachers were found to participate actively in their classes, doing a variety of activities such as solving problems and reading research material on teaching mathematics. Moreover, they had a chance to practice teaching and engage in lesson planning. However, most of the participants claimed to have few opportunities to learn about the use of assessment or the skills they need to become critical teachers, for instance reflection and improvement of practice and awareness of the gaps in their knowledge. Moreover, the results show that the participants had very few opportunities to learn about teaching mathematics to diverse students. That finding coincides with the international outcomes of the TEDS-M study (Tatoo et al., 2012), in which the teachers also reported an apparent lack of knowledge in this area. This deficit and the fact that the participants appear to have few opportunities for reflecting on and enhancing their practice are matters that university authorities and policymakers should concern themselves with, as these are important competencies for teaching mathematics.

Regarding performance on the MCK and MPCK test, the participants had acceptable results, answering correctly approximately $64 \%$ of the MCK tasks and $79 \%$ of the MPCK tasks. If we compare the correct answers by item, the Costa Rican participants performed above the international average in TEDS-M in most items of both constructs (Brese \& Tatoo, 2012). This finding may seem encouraging, but it does not tell us much about the participants' specific teaching strengths or weaknesses, so it must be taken with caution. Nevertheless, it can be observed that algebra was the content area in which the participants performed better, applying was the cognitive domain with more correct answers and curriculum and planning the MPCK sub-domain with better performance, although only $70 \%$ of correct answers were supplied in the first two areas. Thus, further analysis is required to examine the specific knowledge and skills of Costa Rican future teachers, in order to identify strategies for developing and improving their weaker skills during the TEPs. 
It is interesting to analyze the extent to which the opportunities to learn in the TEPs and the participants' performance on the MCK and MPCK are associated. Previous research has stated that "MCK is associated with the number and content of mathematics content courses taken" (Qian \& Youngs, 2016, p. 374). However, the results from the present participants showed that there was no significant correlation between the MCK test results and the number of topics on mathematics studied. The results in the test differed between universities, although they offered similar numbers of topics. For instance, Universities A and C covered 15.1 and 16.4 mathematics content topics, respectively, but the future teachers from University A performed significantly better than those from University C. Likewise, University C students' performance was similar to that of students from University D, although the latter studied fewer topics, 13.7. There was also no evidence of a correlation between the content domains studied (i.e., discrete structures and logic) and the MCK results. The same phenomenon pertained for the MPCK construct.

There is no evidence that either the number of mathematics education pedagogy courses or the OTL teaching methods were correlated with the performance of future teachers on the MPCK questions. This also runs counter to previous results, in which the number of mathematics education pedagogy courses correlated with the teachers' level in the MPCK (Qian \& Youngs, 2016). These results raise a crucial question: if the number or type of content studied in the TEP courses is not related to the participants' performance in MCK and MPCK, then what determines the success or failure in these areas of teacher knowledge? Would that be explained by the quality of the courses or by the teacher educators? The answers to these questions are beyond the scope of this article. However, it can be concluded that improving TEPs requires more than just adding or removing courses.

The findings of this article suggest that more studies should be conducted to analyze the quality of the courses in the TEPs. Although there is, in Costa Rica, a national accreditation system for majors, and two of the universities involved in this study have their study plans accredited, this process does not efficiently evaluate the quality or relevance of the programs offered (Alfaro et al., 2013). In addition, the answers to the MCK and MPCK items should be studied in more detail to gain an overview of the teachers' knowledge and aptitudes for teaching mathematics. Further, research is needed to study future teachers' beliefs about the teaching and learning of mathematics and thereby acquire a full picture of the skills and aptitudes that define competence for teaching (Blömeke \& Kaiser, 2014).

Attention must also be drawn to the absence of private universities from these studies and to emphasize the importance of including them. Previous studies have shown that private universities' study programs include fewer mathematics courses and the pedagogical knowledge offered is weaker than that offered by public universities (Alfaro et al., 2013). Unfortunately, such institutions showed little or no interest in participating in the present study, which made the required data unavailable for the investigation. Add to this the government's lack of hiring strategies that include assessment of the quality of teacher competencies and the increasing possibility of poorly trained teachers reaching the classroom, and the quality of mathematics education is compromised.

\section{Acknowledgements}

We thank the University of Costa Rica for the study grant that supported this research, and all the institutions and individuals that agreed to collaborate.

\section{References}

Alfaro, A. L., Alpízar, M., Morales, Y., Ramírez, M., and Salas, O. (2013). La formación inicial y continua de docentes de matemáticas en Costa Rica. Cuadernos de Investigación y formación en Educación Matemática, 131-179.

Ball, D. L., Thames, M. H., and Phelps, G. (2008). Content knowledge for teaching: What makes it special? Journal of Teacher Education, 59(5), 389-407. DOI: 10.1177/0022487108324554 
Blömeke, S. (2012). Content, professional preparation, and teaching methods: How diverse is teacher education across countries? Comparative Education Review, 56(4), 684-714. DOI: 10.1086/667413

Blömeke, S., and Kaiser, G. (2014) Theoretical framework, study design and main results of TEDS-M. In: Blömeke, S., Hsieh, F. J., Kaiser, G., and Schmidt W. (Eds.) International perspectives on teacher knowledge, beliefs and opportunities to learn. Advances in Mathematics Education (pp. 19-47). Dordrecht: Springer. DOI: 10.1007/978-94-007-6437-8_2

Brese, F., and Tatoo, M. T. (Eds.). (2012). User guide for the TEDS-M International Database. Supplement 4: TEDS-M Released Mathematics and Mathematics Pedagogy Knowledge Assessment Items. Amsterdam, Netherlands: International Association for the Evaluation of Educational Achievement (IEA).

Hill, H. C., Rowan, B., and Ball, D. L. (2005). Effects of teachers' mathematical knowledge for teaching on student achievement. American Educational Research Journal, 42(2), 371-406. DOI: 10.3102/00028312042002371

Hoover, M., Mosvold, R., Ball, D. L., and Lai, Y. (2016). Making progress on mathematical knowledge for teaching. The Mathematics Enthusiast, 13(1), 3-34.

Kaarstein, H. (2014). A comparison of three frameworks for measuring knowledge for teaching mathematics. Nordic Studies in Mathematics Education, 19 (1), 23-52.

Kilpatrick, J., Blume, G., Heid, K., Wilson, J., Wilson, P., and Zbiek, R. (2015). Mathematical understanding for secondary teaching: A framework. In: Heid, K., Wilson, P., and Blume, G. Mathematical understanding for secondary teaching: A framework and classroom-based situations (pp. 9-30). Charlotte, NC: Information Age Publishing.

Koponen, M., Asikainen, M. A., Viholainen, A., and Hirvonen, P. E. (2016). Teachers and their educators: Views on contents and their development needs in mathematics teacher education. The Mathematics Enthusiast, 13(1), 149-170.

MEP, 2012. Programas de Estudio de Matemáticas. I, II, y III Ciclos de la Educación General Básica y Ciclo Diversificado. San José, Costa Rica: Ministerio de Educación Pública.

Monk, D. H. (1994). Subject area preparation of secondary mathematics and science teachers and student achievement. Economics of Education Review, 13(2), 125-145.

OECD (2019), PISA 2018 Results (Volume I): What Students Know and Can Do, PISA, OECD Publishing, Paris, https://doi.org/10.1787/5f07c754-en.

O'Meara, N. (2011). Improving mathematics teaching at second level through the design of a model of teacher knowledge and an intervention aimed at developing teachers' knowledge. [Doctoral dissertation, University of Limerick]. ULIR.

PEN, 2019. Resumen séptimo informe estado de la educación. San José, Costa Rica: Programa Estado de la Nación.

Qian, H., and Youngs, P. (2016). The effect of teacher education programs on future elementary mathematics teachers' knowledge: A five-country analysis using TEDS-M data. Journal of Mathematics Teacher Education, 19(4), 371-396. DOI:10.1007/s10857-014-9297-0

Román, I., and Lentini, V. (2018). “Costa Rica: El estado de políticas públicas docentes. Diálogo Interamericano y Unidos por la educación."https://www.thedialogue.org/wp-content/uploads/2018/08/El-estado-de-politicas-publicas-abril15.pdf,(accessed February 2020)

Rowland, T., Turner, F., Thwaites, A., and Huckstep, P. (2009) Developing primary mathematics teaching: Reflecting on practice with the Knowledge Quartet. London, England: Sage.

Schmidt, W. H., Cogan, L., and Houang, R. (2011a). The role of opportunity to learn in teacher preparation: An international context. Journal of Teacher Education, 62(2), 138-153. DOI:10.1177/0022487110391987

Schmidt, W. H., Houang, R., and Cogan, L. S. (2011b). Preparing future math teachers. Science, 332(603), 1266-1267.

Senk, S. L., Peck, R., Bankov, K., and Tatto, M. T. (2008). Conceptualizing and measuring mathematical knowledge for teaching: Issues from TEDS-M, an IEA cross-national study. In: Mexico: 11th International Congress of Mathematics Education.

Shulman, L. (1986). Those who understand: Knowledge growth in teaching. Educational Researcher, 15(2), 4-14. DOI: $10.2307 / 1175860$

Tatto, M. T. (2016). Mathematics knowledge for teaching at the secondary levels: Methods and evidence from the TEDS-M Study. Cuadernos de Investigación y Formación en Educación Matemática, 101-126.

Tatto, M. T., Schwille, J., Senk, S., Ingvarson, L., Peck, R., and Rowley, G. (2008). Teacher Education and Development Study in Mathematics (TEDS-M): Policy, practice, and readiness to teach primary and secondary mathematics. Conceptual framework. East Lansing, MI: Teacher Education and Development International Study Center, College of Education, Michigan State University.

Tatto, M. T., Peck, R., Schwille, J., Bankov, K., Senk, S. L., Rodriguez, M., Ingvarson, L., Reckase, M., and Rowley, G. (2012). Policy, practice, and readiness to teach primary and secondary mathematics in 17 countries: Findings from the IEA Teacher Education and Development Study in Mathematics (TEDS-M). International Association for the Evaluation of Educational Achievement (IEA). 